\title{
ANÁLISES FíSICO-QUÍMICAS DE SOLO DE TALUDES DE CORTE DE MINERAÇÃO: O CONTEXTO AMBIENTAL DA BACIA HIDROGRÁFICA DO RIO MARANDUBA, UBATUBA/SP
}

\author{
Aline Muniz Rodrigues \\ Universidade Federal do Rio de Janeiro, Departamento de Geografia, Rio de Janeiro, RJ, Brasil \\ alinemrodrigues@live.com \\ Leonardo dos Santos Pereira \\ Universidade Federal do Rio de Janeiro, Departamento de Geografia, Rio de Janeiro, RJ, Brasil \\ leospgeo@gmail.com \\ Maria do Carmo Oliveira Jorge \\ Universidade Federal do Rio de Janeiro, Departamento de Geografia, Rio de Janeiro, RJ, Brasil \\ orofila@gmail.com \\ Antônio José Teixeira Guerra \\ Universidade Federal do Rio de Janeiro, Departamento de Geografia, Rio de Janeiro, RJ, Brasil \\ antoniotguerra@gmail.com
}

\begin{abstract}
RESUMO
A intervenção antrópica sobre os sistemas naturais tem alterado o seu funcionamento e acelerado determinados processos geomorfológicos. A degradação dos solos pode ser considerada uma problemática de proporção mundial, afeta a biodiversidade e a segurança alimentar. Este estudo objetivou identificar as principais atividades que contribuem para a degradação ambiental na bacia hidrográfica do rio Maranduba, Ubatuba/SP. A metodologia se pautou em trabalhos de campo entre os anos de 2014 e 2015 para coleta de amostras de solo e monitoramento das alterações antrópicas através de registro fotográfico. Foram selecionados oito taludes degradados e duas áreas de floresta para a coleta de amostras deformadas e volumétricas de solo, para a determinação da densidade aparente, porosidade total, granulometria, estabilidade de agregados, matéria orgânica e $\mathrm{pH}$. Constatou-se que a mineração em taludes de corte causa grande impacto visual e ambiental, ocasiona a perda da camada mais superficial dos solos, expondo os mesmos à ação dos agentes modeladores do relevo, e acelera a ocorrência da erosão. Portanto, a mineração tende a causar modificações nas propriedades do solo, a partir da intensificação da exploração e posterior abandono dos taludes, tornando necessária a adoção de medidas de recuperação.
\end{abstract}

Palavras-chave: Degradação dos solos. Mineração. propriedades do solo.

\section{PHYSICAL-CHEMICAL SOIL ANALYSIS OF MINING CUT TALUS: THE ENVIRONMENTAL CONTEXT OF THE MARANDUBA WHATERSHED, UBATUBA, SERRA DO MAR REGION, SÃO PAULO STATE, BRAZIL}

\begin{abstract}
Human activities on natural systems have altered its functioning and accelerated certain geomorphological processes. Soil degradation may be considered a global problem, affecting biodiversity and food security. This study aimed to identify the main activities that contribute to environmental degradation in Maranduba drainage basin, Ubatuba Municipality / São Paulo State. The methodology was based on fieldworks between 2014-2015 for soil samples collection and human changes monitoring, through photographic record. Eight degraded talus slopes and two forest areas were selected for deformed and volumetric soil samples collection, for the determination of bulk density, total porosity, soil texture, aggregate stability, organic matter and $\mathrm{pH}$. It was observed that mining in cut talus causes great visual and environmental impacts, resulting on top-soil loss, exposing them to relief modeling agents action, accelerating erosion processes. Therefore, mining tends to cause soil property changes, from the exploitation intensification and subsequent talus abandonment, making it necessary recovery measures adoption.
\end{abstract}

Keywords: Soil degradation. Mining. Soil properties. 


\section{INTRODUÇÃO}

Problemas relacionados à erosão dos solos destacam-se em quase todo o mundo, afetando tanto áreas urbanas quanto rurais. Pesquisas indicam que a perda mundial de solos é de aproximadamente 6 milhões de hectares por ano e a erosão se caracteriza como o processo geomorfológico de maior distribuição geográfica pelo planeta (KLIK e EITZINGER, 2010; GUERRA, 2014; BHATTACHARYYA et al., 2016). A degradação do solo está sendo de 10 a 40 vezes superior às taxas de renovação do mesmo, fato que coloca em risco a sustentabilidade ambiental e a segurança alimentar (PIMENTEL, 2006).

A ação antrópica está associada ao processo de erosão acelerada, contribuindo, de muitas maneiras, para a aceleração das taxas pelas quais os sedimentos são removidos das encostas. $O$ desmatamento, 0 crescimento das cidades e a mineração podem ser consideradas as principais causas da erosão acelerada, resultando em prejuízos ao meio ambiente que podem ser verificados tanto no local (onsite) como em áreas afastadas (offsite), impactando significativamente os corpos d'água (GOUDIE, 1995; FERREIRA et al., 2012; GUERRA e GUERRA, 2013; GUERRA, 2014; GONZÁLEZ-ARQUEROS et al., 2017; GUERRA et al., 2017).

O solo é um recurso natural de grande importância, responsável por permitir o desenvolvimento de diferentes organismos, sendo o alicerce para as atividades humanas. No entanto, encontra-se em processo de degradação, relacionado à sua utilização inadequada, contribuindo, de forma bastante consubstancial, para a intensificação dos processos erosivos e alteração das propriedades físicas e químicas. Pode ser considerado, assim, um recurso natural que o homem tem dado pouca atenção, utilizando-o sem se preocupar com o período de recuperação necessário, ou mesmo negligenciando seu papel para o funcionamento adequado dos sistemas ambientais. Consequentemente, este quadro tem corroborado para o aumento da degradação dos solos, seja na agricultura, com o uso de técnicas de cultivo convencionais ou em áreas urbanas, através da perda crescente de cobertura vegetal (GOUDIE, 1995; FULLEN e CATT, 2004; MORGAN, 2005; GUERRA et al., 2017).

A compreensão acerca das propriedades do solo é fundamental para a escolha das estratégias mais viáveis de uso e manejo do mesmo, visando a sua conservação, uma vez que o conhecimento acerca das características físicas, químicas e mineralógicas do solo é capaz de proporcionar uma avaliação mais detalhada das limitações e potencialidades de determinada área (NANDI e LUFFMAN, 2012; CHENG et al., 2016).

Nesta perspectiva, dentre as justificativas para a realização desta pesquisa, está o fato da área de estudo apresentar atividades que ocasionam degradação ambiental, como a mineração em taludes, levando a perda da qualidade dos solos, mesmo em áreas de preservação ambiental do bioma Mata atlântica. A mineração é uma atividade que ocorre, em grande parte, de forma clandestina, impactando porções significativas da área de estudo, até mesmo na borda do Parque Estadual da Serra do Mar, importante Unidade de Conservação de proteção integral da Mata Atlântica. Desta forma, o conhecimento acerca das características dos solos pode contribuir para sua conservação, através do uso e manejo mais conscientes (FERREIRA et al., 2008; RODRIGUES, 2016).

Por conseguinte, este trabalho possui como objetivo analisar as propriedades físicas e químicas do solo de taludes de corte degradados pela atividade de mineração na bacia hidrográfica do rio Maranduba, visto que tal atividade tende a corroborar para a ocorrência da erosão acelerada, nesta área que apresenta fragilidade ambiental natural, com intensa pluviosidade e relevo acidentado. Objetiva-se ainda apresentar o contexto ambiental da bacia, a partir da utilização de fotografias dos anos de 2014 e 2015. Busca-se, assim, contribuir com estudos que possibilitem a conservação dos solos, acreditando que as pesquisas são meios essenciais de difusão do conhecimento.

A referência ao termo talude está relacionado ao caráter antrópico que se faz predominante nas encostas da bacia analisada, com mudanças na cobertura vegetal e declividade da encosta, pois como ressaltam Cunha et al. (1991), talude de corte é resultante de algum processo de escavação promovido pelo homem na encosta.

\section{CARACTERÍSTICAS DA ÁREA DE ESTUDO}

A bacia hidrográfica do rio Maranduba (Figura 1) está localizada no município de Ubatuba, litoral norte do Estado de São Paulo. Possui aproximadamente $39 \mathrm{~km}^{2}$ de área total, composta por paisagem de inestimável beleza formada pelas praias e pelo relevo montanhoso da Serra do Mar, situado em domínio do bioma Mata Atlântica.

$\begin{array}{llllll}\text { Caminhos de Geografia } & \text { Uberlândia - MG } & \text { v. 19, n. } 67 & \text { Set/2018 } & \text { p. 157-174 } & \text { Página } 158\end{array}$


Figura 1: Bacia hidrográfica do rio Maranduba e os pontos de coleta de amostras de solo.

\section{$45^{\circ} 20^{\prime} 0^{\prime \prime} \mathrm{W} \quad 45^{\circ} 19^{\prime} 0^{\prime \prime} \mathrm{W} \quad 45^{\circ} 18^{\prime} 0^{\prime \prime} \mathrm{W} \quad 45^{\circ} 17^{\prime} \mathrm{O}^{\prime \prime} \mathrm{W} \quad 45^{\circ} 16^{\prime} \mathrm{O}^{\prime \prime} \mathrm{W} \quad 45^{\circ} 15^{\prime} \mathrm{O} \mathrm{W} \quad 45^{\circ} 14^{\prime} 0^{\prime \prime} \mathrm{W} \quad 45^{\circ} 13^{\prime} 0^{\prime \prime} \mathrm{W} \quad 45^{\circ} 12^{\prime} \mathrm{O}^{\prime \prime} \mathrm{W} \quad 45^{\circ} 11^{\prime} \mathrm{O}^{\prime \prime} \mathrm{W} \quad 45^{\circ} 10^{\prime} \mathrm{O}^{\prime \prime} \mathrm{W}$}

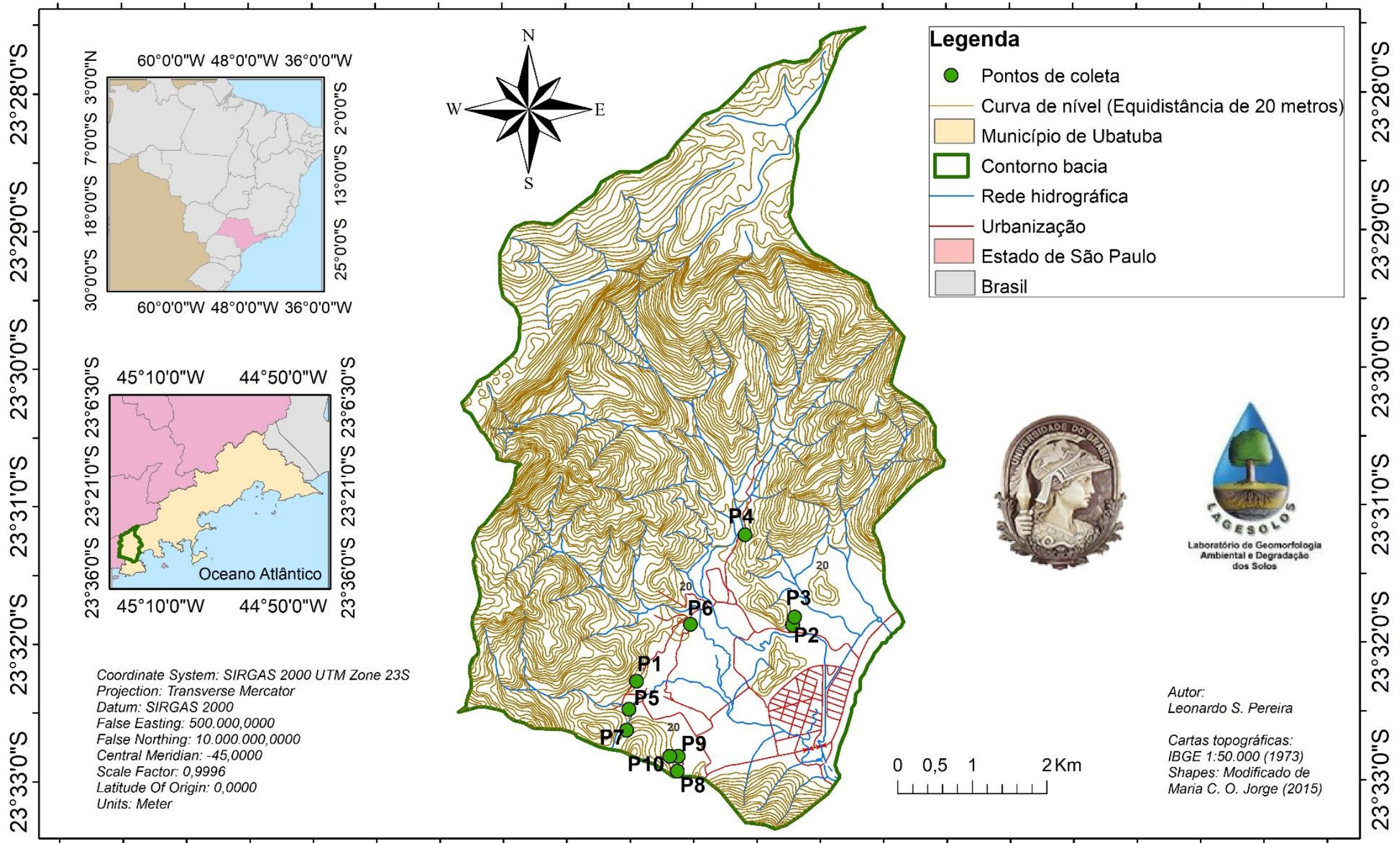

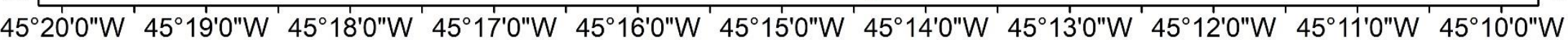


As maiores altitudes registradas na bacia são de 1.100 metros no topo da Serra do Mar, e os principais agentes modeladores são os rios Maranduba, Araribá e seus tributários. Nas rupturas das vertentes e declives acentuados ocorrem corredeiras e cachoeiras de grande beleza, as quais, na medida em que as declividades suavizam, diminuem de força e intensidade até alcançarem a planície. O rio Maranduba nasce no alto das escarpas da Serra do Mar, suas nascentes ficam localizadas a cerca de 900 metros de altitude, possui elevada energia, originando corredeiras e cachoeiras, carreando rochas e material sedimentar que se depositam em declividades mais suaves. Contudo, quando o rio alcança o terço inferior da vertente, cerca de 70 metros de altitude, suas margens começam a ser ocupadas, gerando impactos que se alastram até a desembocadura (BUZATO, 2012; JORGE, 2014 e 2017; RODRIGUES, 2016).

Ubatuba possui cerca de $80 \%$ de seu território situado em Unidade de Conservação (Parque Estadual da Serra do Mar e Parque Nacional da Serra da Bocaina), contemplando uma porção representativa em bom estado de conservação da Mata Atlântica na região Sudeste do país. Contudo, um expressivo crescimento populacional pode ser verificado, sobretudo a partir da década de $1980 \mathrm{com}$ a abertura da Rodovia BR 101 (Rio-Santos - década de 1970), facilitando o acesso ao litoral, causando grande pressão sobre as áreas naturais, à medida que o modo de uso e ocupação das terras foi modificado. Desta forma, apesar da presença de unidades de conservação, o município apresenta uma série de mudanças em sua estrutura socioeconômica e ambiental, causado pela pressão exercida pelo crescimento populacional mesmo em áreas de preservação ambiental (TOMINAGA, 2007; BUZATO, 2012; JORGE, 2014).

O clima característico é o tropical litorâneo úmido, com temperatura média anual de $21^{\circ} \mathrm{C}$. Ocorre o domínio das massas tropicais, com constante atuação de frentes frias, as quais conjugadas às características morfológicas e altimétricas da Serra do Mar são responsáveis por grande parte dos eventos pluviais extremos (SANT'ANNA NETO, 1990; TAVARES et al., 2002).

$\mathrm{Na}$ bacia do rio Maranduba, Pereira et al. (2016) constataram, a partir da leitura diária de um pluviômetro instalado há sete anos no bairro Araribá, que os meses de janeiro e dezembro apresentaram maiores amplitudes nas médias mensais de 2009 a 2015, caracterizando-se como meses mais úmidos, enquanto que os meses mais secos foram junho e julho (Tabela 1). Os últimos 7 anos foram aqueles que ficaram abaixo da média de 30 anos de Ubatuba, sendo que 2015 foi o ano com menor acumulado pluvial $(1.440,5 \mathrm{~mm})$.

O município está localizado em área cujo domínio pertence às rochas do embasamento cristalino, agrupadas no Complexo Costeiro, estruturando a Serra do Mar. Ocorre o predomínio dos Cambissolos, associados às escarpas. Os Neossolos Litólicos podem ser encontrados em relevos de elevada declividade, nas altas vertentes e topos de morros. Comumente, pode-se observar a ocorrência de movimentos de massa, condicionados, principalmente, pelas acentuadas declividades e agravados por processos antrópicos. Os movimentos do tipo rastejo e escorregamento são predominantes, oriundos de escorregamentos localizados a montante, além da queda de blocos, muito condicionada pelas estruturas das rochas (HASUI et al., 1981 e 1993; ROSSI, 1999; FIERZ, 2008; JORGE, 2014).

Apesar de existirem severas restrições para a ocupação territorial e uso dos recursos naturais, as condições ambientais naturais são afetadas cotidianamente por fatores externos, colocando em risco a frágil estabilidade geodinâmica presente no revelo montanhoso da Serra do Mar. Desta forma, a mineração pode ser entendida como um importante elemento modificador das condições ambientais no Litoral Norte de São Paulo, em especial, no município de Ubatuba, explorando bens de uso direto na construção civil, como areia, saprolito, brita e rocha ornamental (FERREIRA et al., 2008; JORGE, 2014; RODRIGUES, 2016; RODRIGUES et al., 2016).

\section{MATERIAIS E MÉTODOS}

\section{COLETA DE AMOSTRAS DE SOLO}

Foram selecionadas oito áreas degradadas e duas áreas de floresta na bacia hidrográfica do rio Maranduba, através de trabalhos de campo em 2014 e 2015, para coleta de amostras de solo (Figura 1). Coletaram-se 10 blocos de solo e amostras volumétricas em triplicata, totalizando 36 amostras volumétricas (nos pontos P7 e P8, as amostras foram coletadas em duas profundidades). Os trabalhos de campo objetivaram ainda monitorar as alterações antrópicas nas áreas anteriormente selecionadas, através de registro fotográfico nesses dois anos.

\begin{tabular}{llllll}
\hline Caminhos de Geografia & Uberlândia - MG & v. 19, n. 67 & Set/2018 & p. 157-174 Página 160
\end{tabular}


As amostras de solo em áreas degradadas foram coletadas em taludes, onde o horizonte de saprolito se fez presente. As encostas que apresentaram horizonte $A$ foram poucas, visto que o tipo de degradação mais comum na bacia hidrográfica do rio Maranduba está relacionado à retirada clandestina de material de empréstimo para a construção civil, onde o solo mais superficial é removido. Portanto, em áreas onde foi possível constatar a presença do horizonte $A$, sendo também possível o acesso, foram coletadas amostras de $0-20 \mathrm{~cm}$ e de $20-40 \mathrm{~cm}$ de profundidade em triplicata (P7 e P8) (Figura 2A). Em áreas onde tal constatação e o acesso não foram possíveis, foram coletadas amostras somente na parte intermediária do talude em triplicata (P1, P2, P3, P4, P5 e P6) (Figura 2B). Nas duas áreas de floresta (P9 e P10) as amostras foram coletadas de $0-20 \mathrm{~cm}$ de profundidade (Tabela 2).

Figura 2: Coleta de amostras de solo de $0-20$ e de $20-40 \mathrm{~cm}$ de profundidade (A) e na parte intermediária do talude (B).

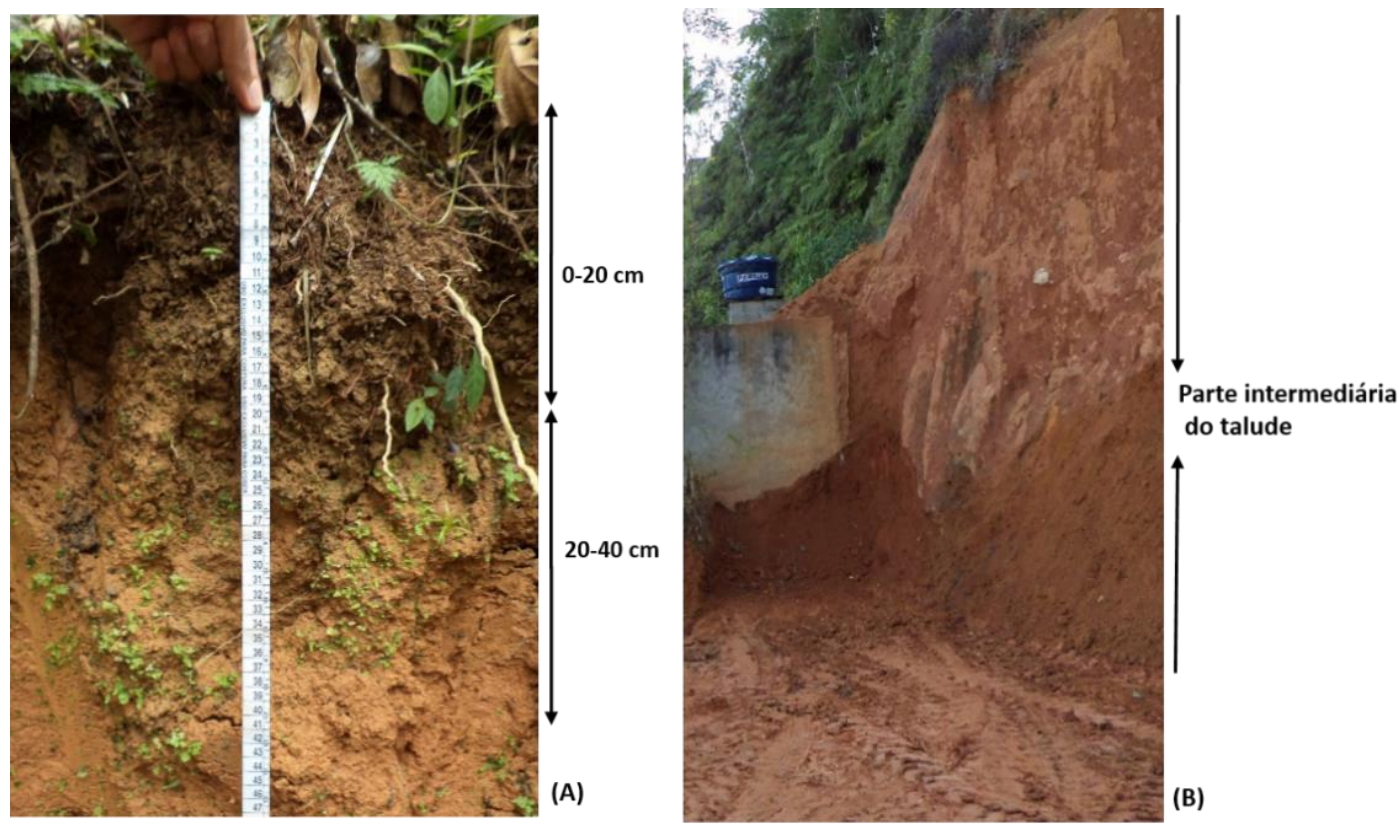

Fotos: ALINE M. RODRIGUES (2015).

Tabela 2: Características dos pontos de coleta de amostras.

\begin{tabular}{|c|c|c|c|}
\hline $\begin{array}{c}\text { Pontos de } \\
\text { Coleta }\end{array}$ & Localização UTM & $\begin{array}{c}\text { Elevação em Relação ao } \\
\text { Nível do Mar }\end{array}$ & $\begin{array}{c}\text { Inclinação do } \\
\text { Talude }\end{array}$ \\
\hline P1 & $0473718 / 7396899$ & 9 metros & $80^{\circ}$ \\
\hline P2 & $0475815 / 7397652$ & 13 metros & $55^{\circ}$ \\
\hline P3 & $0475841 / 7397762$ & 8 metros & $78^{\circ}$ \\
\hline P4 & $0475179 / 7398867$ & 6 metros & $61^{\circ}$ \\
\hline P5 & $0473618 / 7396524$ & 15 metros & $66^{\circ}$ \\
\hline P6 & $0474444 / 7397663$ & 6 metros & $87^{\circ}$ \\
\hline P7 & $0473587 / 7396241$ & 13 metros & $80^{\circ}$ \\
\hline P8 & $0474218 / 7395531$ & 9 metros & $45^{\circ}$ \\
\hline P9 & $0474281 / 7395894$ & 5 metros & $37^{\circ}$ \\
\hline P10 & $0474165 / 7395895$ & 13 metros & $40^{\circ}$ \\
\hline
\end{tabular}


A coleta das amostras volumétricas foi realizada através da utilização de anéis de Kopeck de 100 $\mathrm{cm}^{3}$, visando a determinação da densidade aparente do solo, da porosidade total, granulometria, $\mathrm{pH}$ e teor de matéria orgânica. Os blocos de solo, por sua vez, foram coletados para a determinação da estabilidade dos agregados por via úmida.

\section{ANÁLISES DAS PROPRIEDADES FÍSICO-QUÍMICAS DO SOLO}

Utilizando-se a metodologia da Embrapa (2011), foram realizadas análises físicas de densidade aparente e porosidade total (Método do anel volumétrico) e análise granulométrica (Método da pipeta). Bem como análises químicas de pH (Princípio da medição do potencial eletronicamente por meio de eletrodo combinado imerso em suspensão solo:água) e matéria orgânica (Princípio da oxidação da matéria orgânica via úmida com dicromato de potássio em meio sulfúrico).

Para análise física da estabilidade dos agregados por via úmida foi utilizado o equipamento denominado "Yoder", de modo a medir a quantidade e a distribuição do tamanho dos agregados que são estáveis em água, tornando possível, assim, entender a sua estabilidade e resistência (YODER, 1936). Calculou-se o Diâmetro Médio Ponderado (DMP), Diâmetro Médio Geométrico (DMG) e Índice de Estabilidade dos Agregados (IEA) de acordo com Castro Filho et al. (1998). O DMP é tanto maior quanto mais elevada for a porcentagem de agregados grandes que ficam retidos nas peneiras com malhas maiores. O DMG diz respeito à estimativa do tamanho da classe de agregados de maior ocorrência. O IEA está relacionado à medida da agregação total do solo, não considera a distribuição por classes de agregados (CASTRO FILHO et al.,1998).

As análises laboratoriais foram realizadas no Laboratório de Geomorfologia Maria Regina Mousinho de Meis, do Departamento de Geografia da Universidade Federal do Rio de Janeiro.

\section{RESULTADOS E DISCUSSÃO}

\section{PROPRIEDADES FÍSICO-QUIMIICAS DO SOLO}

Os pontos $\mathrm{P} 1$ a $\mathrm{P} 6$, onde as amostras foram coletadas na parte intermediária dos taludes, as médias de densidade aparente variaram entre $1,3 \mathrm{~g} / \mathrm{cm}^{3}$ e $1,6 \mathrm{~g} / \mathrm{cm}^{3}$, refletindo a influência da característica textural dos solos analisados, com a predominância de frações de areia, além do peso exercido pelas camadas superiores do solo. A densidade aparente está relacionada ao grau de compactação do solo, podendo alterar consideravelmente a rede de poros, aumentando a resistência mecânica à penetração de raízes e, consequentemente, à penetração da água, uma vez que as raízes funcionam como caminhos preferencias para a infiltração da água no solo (REICHERT et al., 2010). Desta forma, a porosidade total variou entre $40,1 \%$ e $51,5 \%$ (Tabela 3), de acordo com o comportamento de solos arenosos, onde a porosidade total tende a variar entre 35\% e 50\% (PREVEDELLO, 1996).

Em relação ao ponto $\mathrm{P} 7$, observa-se que a densidade aparente foi mais elevada de $20-40 \mathrm{~cm}$ de profundidade $\left(1,6 \mathrm{~g} / \mathrm{cm}^{3}\right)$, enquanto que de $0-20 \mathrm{~cm}$ a densidade aparente foi de $1,3 \mathrm{~g} / \mathrm{cm}^{3}$. Como são inversamente proporcionais, a porosidade total foi mais elevada de $0-20 \mathrm{~cm}(48,2 \%)$ do que de $20-40$ $\mathrm{cm}(38,8 \%)$. Por sua vez, P8 apresentou comportamento semelhante, de $0-20 \mathrm{~cm}$ de profundidade apresentou $0,9 \mathrm{~g} / \mathrm{cm}^{3}$ de densidade aparente e $61,4 \%$ de porosidade total, enquanto que de $20-40 \mathrm{~cm}$ apresentou $1,3 \mathrm{~g} / \mathrm{cm}^{3}$ de densidade aparente e $47,4 \%$ de porosidade total (Tabela 3).

Foi possível constatar, então, a tendência verificada por Kiehl (1979), Brady (1989), Fullen e Catt (2004), Fontana et al. (2010) e Vezzani e Mielniczuk (2011), onde a densidade aparente tende a aumentar de acordo com a profundidade do solo, em virtude da redução dos teores de matéria orgânica e, consequentemente, da agregação, bem como do peso exercido pelas camadas superiores do solo. Cabe ressaltar que na profundidade de $20-40 \mathrm{~cm}$ P8 e P9 apresentaram diminuição nos teores de matéria orgânica, o que pode ter ocasionado o aumento da densidade aparente e diminuição da porosidade total nesta profundidade, pois a matéria orgânica é considerada um importante constituinte do solo, que permite maior agregação e coesão entre as partículas, tornando o solo mais poroso e menos denso.

As áreas de floresta (P9 e P10) apresentaram densidade aparente de $1,1 \mathrm{~g} / \mathrm{cm}^{3}$ e $1,2 \mathrm{~g} / \mathrm{cm}^{3}$ e a porosidade total foi de $52,0 \%$ e $51,0 \%$, respectivamente, refletindo a boa estrutura do solo (Tabela 3 ). Como ressaltam Brady (1989) e Camargo e Alleoni (1997) o solo entendido como "ideal" deve apresentar porosidade total por volta de $50 \%$. Nesta perspectiva, a densidade aparente e a

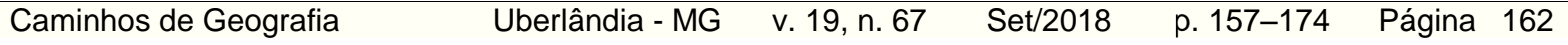


porosidade total das amostras analisadas parecem demonstrar a importância da cobertura vegetal para o bom funcionamento do sistema solo. Tal fato pôde ser verificado, sobretudo, através dos resultados das áreas de floresta em comparação com as demais áreas sujeitas à exploração mineral, onde a cobertura vegetal foi eliminada.

Os resultados da análise granulométrica das amostras coletadas demonstram que os solos dos taludes apresentam taxas mais elevadas da fração areia, onde a classificação textural variou entre franco arenoso, franco areno-argiloso, argiloso e franco. Cabe salientar que, embora a fração areia tenda a ser menos susceptível ao arraste, de acordo com o seu tamanho de grão, ela não possui as propriedades da fração argila que promovem a agregação das partículas do solo (maior força de coesão), podendo se tornar mais propensa à erosão (MORGAN, 2005). Contudo, a retirada da cobertura vegetal conjugada a instabilidade causada pela extração de material de empréstimo, em áreas de grande declividade e pluviosidade intensa, podem tornar esses taludes mais sujeitos à ação dos processos erosivos (RODRIGUES, 2016).

O ponto P5 diferenciou-se dos demais apresentando taxa mais elevada da fração argila $(55,1 \%)$, constituindo um solo de textura argilosa (Tabela 3). Acredita-se que a composição granulométrica argilosa pode ter sido originada por material erodido das vertentes da Serra do Mar, que se depositam no sopé das encostas, formando os colúvios.

Nos pontos de coleta P7 e P8, onde foi possível realizar a coleta tanto de $0-20 \mathrm{~cm}$ quanto de $20-40$ $\mathrm{cm}$ de profundidade, os resultados demonstram também a presença mais elevada da fração areia de 0-20 cm de profundidade, enquanto que de $20-40 \mathrm{~cm}$ ocorre um aumento da fração argila. Observase, assim, o aumento da concentração de argila com a profundidade, uma vez que as partículas menores tendem a ser transportadas do topo do solo pela ação da água. As áreas de floresta, P9 e P10, apresentaram característica semelhante, com porcentagens mais elevadas da fração areia (54,4\% e 50,6\%, respectivamente), conferindo ao solo classificação textural franco areno-argiloso (Tabela 3).

Na acepção de Rossi (1999), os solos do litoral do estado de São Paulo são bastante diversificados, sendo que nas escarpas e planaltos ocorre a predominância de Cambissolos, de textura argilosa e areno-argilosa. No sopé das encostas formam-se comumente taludes de detritos, a partir de materiais heterogêneos, como grandes blocos rochosos. Tais taludes são formados pelo escoamento pluvial em episódios de enxurradas e por processos de movimentos de massa, que ocorrem ao longo da evolução temporal das escarpas. Portanto, em áreas situadas no sopé da Serra do Mar, originam-se os colúvios, formados por material erodido das vertentes, contribuindo para a formação de solos mais profundos. Santos (2004) finaliza ressaltando que os colúvios na Serra do Mar são originados a partir de rastejo, escorregamentos ou erosão, e podem ser encontrados nas áreas mais baixas da vertente.

Segundo Suzuki et al. (2008) e Klein e Klein (2015), a granulometria é a característica que menos se altera com o passar do tempo, visto que é inerente aos fatores de formação do solo, especialmente o material de origem. Nesta perspectiva, entende-se que a predominância das frações granulométricas encontradas nos taludes analisados está relacionada ao saprolito. Trata-se de um material incoerente, pouco intemperizado, que conserva vestígios da estrutura original, apresentando comumente textura mais arenosa, como encontrado na maioria das análises. No estágio final da decomposição, pode-se encontrar textura mais argilosa, tendo em vista a atuação do processo de intemperismo (IPT, 2003).

McQueen e Scott (2009), por sua vez, salientam que saprolito pode ser entendido como uma zona que compõe a estrutura do regolito e que ainda preserva as características do tecido primário rochoso, mas que também apresenta algum sinal de intemperismo químico. No interior do saprolito, podem ocorrer zonas mais ou menos intemperizadas: a camada mais baixa corresponde a zona menos alterada quimicamente (menos de $20 \%$ de minerais alteráveis), geralmente contém evidências do intemperismo mais recente. O saprolito superior tende a apresentar alteração de todos os minerais primários, com exceção dos quimicamente mais resistentes, como também a destruição dos minerais secundários menos estáveis.

Em relação à estabilidade de agregados foram verificados, predominantemente, valores baixos de IEA de P1 a P6 (Tabela 3), o qual representa a agregação total do solo e quanto mais próximo de 100\%, maior será a estabilidade dos agregados em água (SILVA e MIELNICZUK,1997). Logo, tais taludes apresentam valores de IEA distantes de $100 \%$, evidenciando, assim, que os agregados nesses taludes estão susceptíveis à desagregação pela ação da água, relacionado à falta de matéria 
orgânica, responsável por conferir maior agregação ao solo, devido sua ação cimentante (VEZZANI e MIELNICZUK, 2011).

Os valores de DMP e DMG mais elevados nos pontos $\mathrm{P} 7$ e P8 refletem a importância da vegetação para o bom funcionamento dos solos, onde a matéria orgânica funciona como elemento indispensável para a formação de agregados. Lima et al. (2003) salientam a redução do DMP em profundidade, relacionando este fato às reduções nos teores de matéria orgânica. A mesma situação pôde ser observada por Suzuki et al. (2014), ao realizarem estudo de impacto sob Argissolo Vermelho submetido a diferentes usos. Castro Filho et al. (1998), por sua vez, ressaltam que a presença de agregados grandes tende a conferir ao solo resistência à erosão, uma vez que os espaços porosos entre os agregados tendem a ser maiores, aumentando a infiltração da água da chuva e, consequentemente, diminuindo a erosão do solo.

Nas áreas de floresta o IEA foi de 98,2\% em P9 e 90,3\% em P10 (Tabela 3), demonstrando a maior estabilidade de agregados em água, o que, por consequência, confere ao solo maior resistência à erosão, pois como ressaltam Guerra e Cunha (1996), a estabilidade dos agregados exerce papel relevante na erodibilidade dos solos, à medida que a infiltração da água ocorre mais rapidamente se o solo for composto por agregados grandes e estáveis, reduzindo as taxas de escoamento superficial. Castro Filho et al. (1998), Brady e Weil (2008) e Torres et al. (2015) salientam que o IEA depende de uma série de fatores, como teor de matéria orgânica, óxidos de ferro e alumínio, além da presença de raízes de plantas, pois a ação mecânica das raízes contribui para o agrupamento dos microagregados, formando macroagregados, de modo a favorecer a manutenção da estabilidade de agregados.

Conclui-se, portanto, que os parâmetros de avaliação de estabilidade de agregados obtiveram correlação significativa com os teores de matéria orgânica. De acordo com Fontana et al. (2010), o DMP possui correção significativa e positiva com a matéria orgânica, independentemente dos solos e da profundidade. Já Portugal et al. (2010) e Marchini et al. (2015) ressaltam a importância das substâncias húmicas na agregação do solo. Constata-se que os solos analisados parecem apresentar baixa capacidade de proteção da matéria orgânica, onde a formação de agregados estáveis tende a ser prejudicada pela existência de minerais da fração areia, o que confere ao sistema solo maior susceptibilidade à degradação, pois a predominância da areia tende a promover fragilidade natural na formação e estabilização de agregados (VEZZANI e MIELNICZUK, 2011; CARVALHO et al., 2014).

Em relação ao de $\mathrm{pH}$, os resultados demonstram a existência de solos ácidos, com valores entre 3,5 e 5,1 (Tabela 3). Jorge (2014) ao analisar o pH de amostras coletadas em uma trincheira em área de planície no município de Ubatuba, também constatou a presença de solos ácidos, com pH variando entre 4,02 e 4,71. Resultados semelhantes também foram observados por Pereira (2015), o qual encontrou $\mathrm{pH}$ de 4,9 em ambientes degradados na bacia hidrográfica do rio Maranduba, enfatizando, assim, a predominância de solos ácidos na área. Rossi (1999), por sua vez, salienta que o pH encontrado em solos de Ubatuba dificilmente ultrapassa o valor de 5,0, tendo em vista os elevados teores de carbono orgânico, o que eleva os valores de alumínio trocável e propicia alta saturação por alumínio.

Os resultados referentes às porcentagens de matéria orgânica presente nos solos dos taludes $\mathrm{P} 1$, $\mathrm{P} 2$, P3, P4, P5 e P6 foram baixas, variando entre $0,3 \%, 1,4 \%, 0,5 \%, 0,7 \%, 1,2 \%, 0,4 \%$, respectivamente (Tabela 3). Tendo em vista que a coleta de amostras foi realizada na parte intermediária desses taludes, onde a presença da matéria orgânica tende a ser naturalmente menor do que na parte mais superficial, pois como chamam a atenção Zinn et al. (2007; 2011), a variação na quantidade de matéria orgânica do solo é dependente de uma série de fatores, como os resíduos acumulados na superfície, clima, textura e profundidade do solo.

Logo, analisando os resultados nos taludes P7 e P8, observou-se maior presença da matéria orgânica de $0-20 \mathrm{~cm}$ de profundidade em ambos os pontos $(5,0 \%$ e $7,6 \%$, respectivamente), enquanto que de $20-40 \mathrm{~cm}$ a quantidade de matéria orgânica diminuiu também em ambos os pontos $(2,3 \%$ e $2,1 \%$, respectivamente) (Tabela 3$)$. Tal fato tende a estar relacionado à presença da vegetação na parte superficial do solo, conferindo maiores taxas de matéria orgânica nesta profundidade, pois os vegetais são os principais responsáveis pela adição ao solo de compostos orgânicos primários (VEZZANI e MIELNICZUK, 2011; CARVALHO, 2015). Os taludes P7 e P8, diferentemente dos demais, começaram a ser explorados recentemente, por isso acredita-se que pode ter ocorrido maior influência da vegetação no solo, o que permitiu que os resultados das porcentagens de matéria orgânica fossem mais elevados. Porém, a tendência é que os solos de tais taludes percam cada vez mais matéria orgânica, a partir do avanço da mineração ilegal.

$\begin{array}{llllll}\text { Caminhos de Geografia } & \text { Uberlândia - MG } & \text { v. 19, n. } 67 & \text { Set/2018 } & \text { p. 157-174 } & \text { Página } 164\end{array}$


As áreas de floresta (P9 e P10) apresentaram porcentagens mais elevadas de matéria orgânica (11,0\% e 9,3\%, respectivamente) (Tabela 3), tendo em vista a conservação da vegetação superficial. Por conseguinte, deve-se atentar para a necessidade de conservação da cobertura vegetal, sobretudo na presente área de estudo, uma vez que os solos aqui analisados possuem porcentagens mais elevadas da fração areia, e é sabido que os solos arenosos, em geral, apresentam comumente menor teor de matéria orgânica do que solos argilosos. A matéria orgânica ainda é considerada altamente sensível às alterações no uso e manejo, podendo ser perdida rapidamente, sendo que valores inferiores a 3,5\% podem proporcionar instabilidade e maior suscetibilidade dos solos à erosão (FULLEN e CATT, 2004; MIELNICZUK, 2008; WINCK et al., 2014; GUERRA et al., 2017).

$\mathrm{Na}$ acepção de Guerra e Cunha (1996), os desequilíbrios que ocorrem nas encostas possuem influência fundamental do clima e de certos atributos que fazem parte das características das mesmas, como a topografia, geologia, grau de intemperismo e solo, além do fator antrópico, como o tipo de ocupação e uso. Nesse sentido, a ação antrópica nas encostas, sobretudo em relação à retirada da cobertura vegetal, pode corroborar para a ocorrência de desequilíbrios, visto que a remoção da vegetação tende a resultar no aumento das taxas de erosão, pois acarreta na formação de crostas na superfície do solo, produzindo uma camada impermeável que, consequentemente, impede a infiltração. Logo, a manutenção da vegetação contribui para a estabilidade das encostas, onde as raízes fornecem o reforço e contenção mecânica, boa hidrologia do solo, facilitando a infiltração da água e diminuindo o escoamento superficial (MORGAN e RICKSON, 1995).

Assim, a manutenção da cobertura vegetal se faz necessária, de modo a conferir ao solo maiores teores de matéria orgânica, além da proteção contra a ação das gotas de chuva, as quais podem resultar na aceleração da erosão dos taludes, uma vez que a retirada da cobertura vegetal da encosta tende a ser a primeira iniciativa para a exploração mineral, o que pode acarretar em uma série de impactos ao sistema solo. A compreensão sobre as características físico-químicas do solo pode contribuir para a conservação de sua qualidade, corroborando para a manutenção do equilíbrio dos sistemas ambientais, além de poder contribuir para o uso e manejo mais adequado da área de estudo.

\section{CONTEXTO AMBIENTAL DA BACIA HIDROGRÁFICA DO RIO MARANDUBA}

A área de estudo é marcada pela intensificação das perturbações antrópicas sobre os sistemas naturais, onde o aumento dos loteamentos irregulares e a exploração mineral clandestina podem ser consideradas as principais atividades que corroboram para a degradação ambiental, com perdas significativas da cobertura vegetal. A partir do crescimento da atividade turística e da especulação imobiliária, as famílias de baixo poder aquisitivo passaram a ocupar áreas inadequadas, como as encostas íngremes localizadas na borda do Parque Estadual da Serra do Mar, áreas que apresentam risco de ocupação, tendo em vista os índices pluviométricos elevados e o forte relevo formado pela Serra do Mar, com eventos regulares de rolamentos de blocos rochosos (JORGE, 2014; RODRIGUES, 2016) (Figura 3).

Figura 3: Habitação localizada ao sopé de encosta (A); blocos rochosos arredondados depositados próximo às casas $(B)$
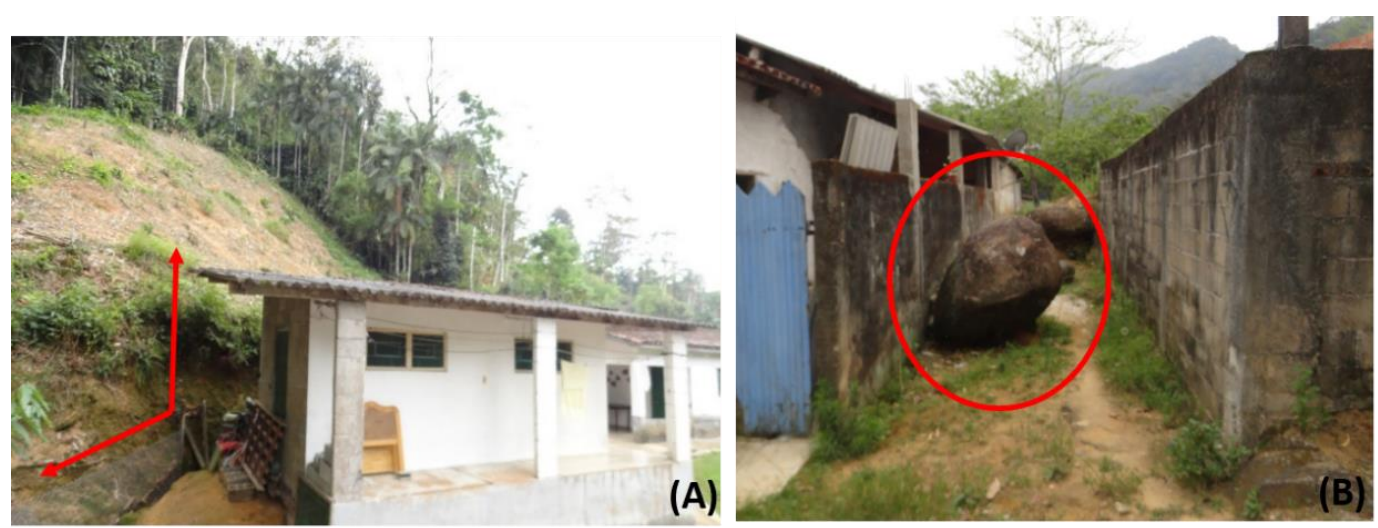

Fotos: ALINE M. RODRIGUES (2014) 
A exploração mineral se caracteriza por ser uma atividade responsável por proporcionar impacto visual e ambiental, espalhando-se pelas encostas íngremes, localizadas na bacia do rio Maranduba. O saprolito é explorado para ser usado nas misturas de cimento e areia na construção civil, foram contabilizados mais de 10 locais de exploração mineral clandestina, situados na borda do Parque Estadual da Serra do Mar (JORGE, 2014; RODRIGUES, 2016).

Esta atividade ocasiona transformação da paisagem, através do aumento do desmatamento e escavação, causando instabilidade nas encostas, intensificando a ocorrência de deslizamentos e queda de blocos. A geometria original da encosta altera-se por meio da extração do saprolito, formando taludes irregulares e íngremes, com cavidades e buracos, fato também verificado por Ferreira et al. (2008). Com o início do processo de escavação da encosta para a retirada de material de empréstimo, ocorre a eliminação da cobertura vegetal, expondo o solo e o saprolito aos agentes modeladores do relevo (Figura 4).

Figura 4: Talude degradado pela exploração mineral ilegal, em novembro de 2014 (A); mesmo talude em agosto de 2015 (B), nota-se o ganho de altura decorrente do processo de escavação.
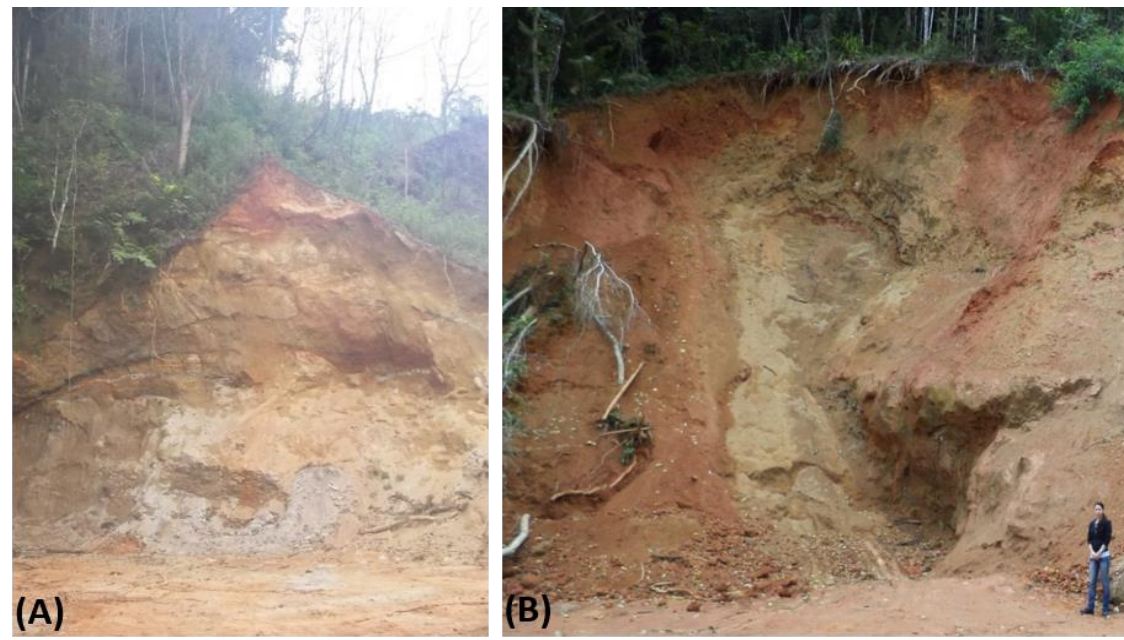

Fotos: ALINE M. RODRIGUES.

A ação fiscalizadora do Poder Público não apresenta eficiência para coibir tal atividade, pois a exploração mineral acontece com alta regularidade, uma vez que não necessita de tecnologias sofisticadas. Nos taludes visitados foi possível perceber a presença de marcas deixadas pela utilização de retroescavadeira para a retirada de material, demonstrando que a exploração acontece cotidianamente, sem qualquer preocupação com a finalização correta da lavra, potencializando a ocorrência de impacto ambiental.

Nestes taludes, em grande parte, há a presença de blocos rochosos que ficam susceptíveis à quedas e rolamentos (Figura 5), visto que as empresas de mineração clandestinas rotineiramente abandonam os taludes anteriormente explorados, colocando em risco a manutenção do equilíbrio da encosta, como também à vida das populações vizinhas, pois como destaca Silva (1995) estas áreas são propícias a serem ocupadas pelas populações de baixa renda, de acordo com as facilidades encontradas, como a prévia remoção da cobertura vegetal e a existência de vias de acesso implantadas para a passagem de caminhões e tratores (Figura 6). 
Figura 5: Áreas de exploração mineral com a presença de blocos rochosos.
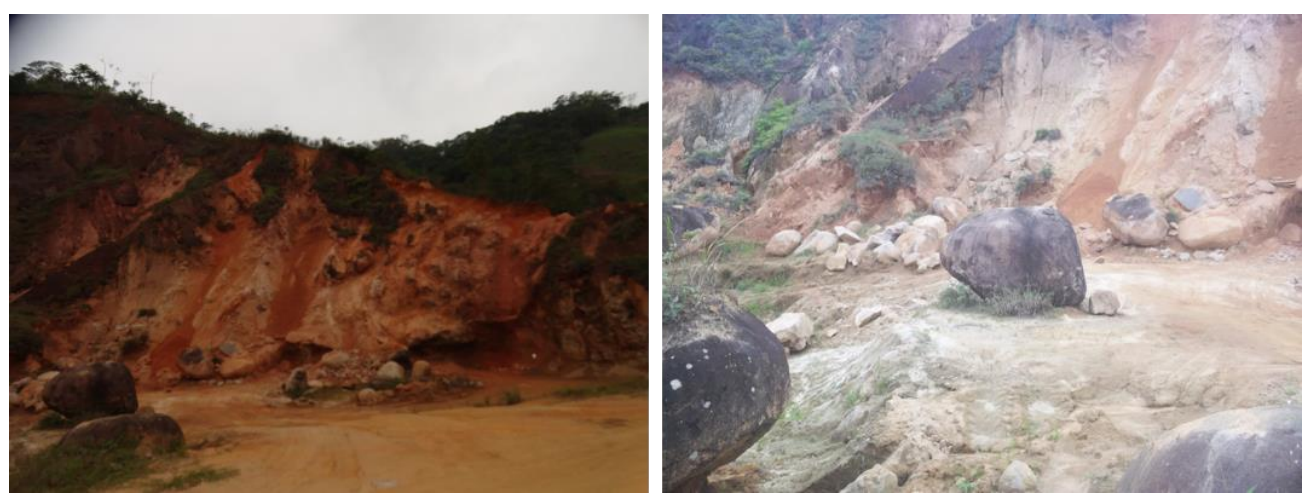

Fotos: ALINE M. RODRIGUES (2015).

Figura 6: Ocupação em área adjacente a talude de corte.

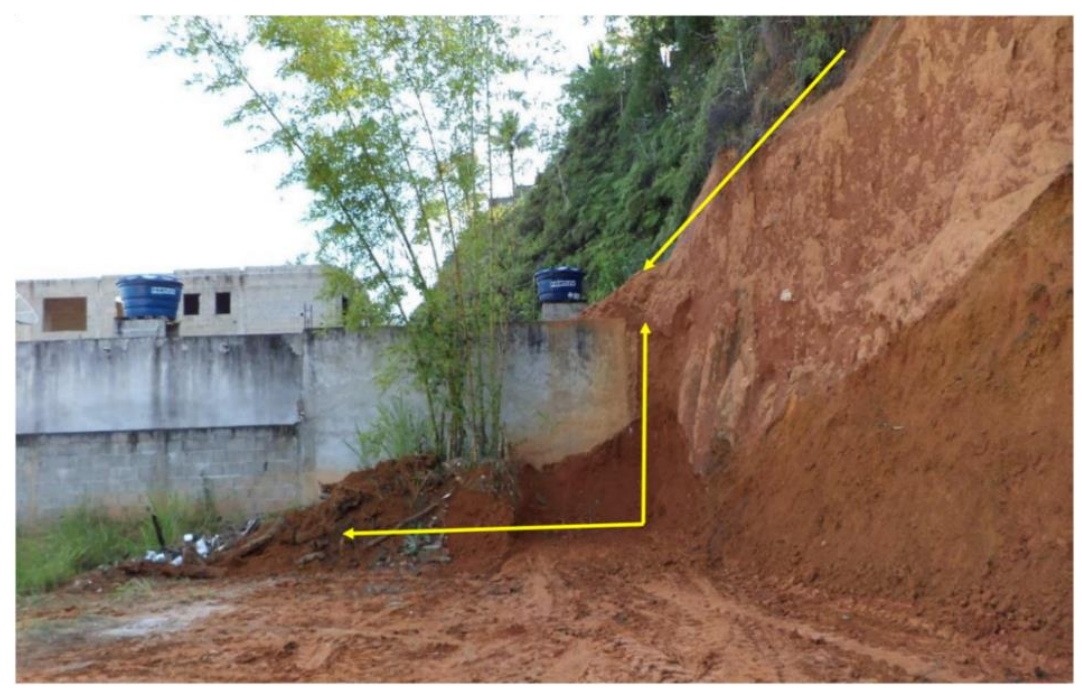

Foto: ALINE M. RODRIGUES (2015).

A ação antrópica nas encostas, a partir de mudanças no uso do solo, pode também alterar a dinâmica fluvial. O desmatamento, construções irregulares nas encostas, mineração, práticas agrícolas, entre outras atividades, tendem a reduzir a capacidade de infiltração e aumentar o escoamento superficial, proporcionando a erosão hídrica nas encostas, e, consequentemente, fornecer maior volume de sedimentos para a calha fluvial, que, por sua vez, pode resultar no assoreamento do leito, bem como em enchentes na planície de inundação. Segundo Ferreira et al. (2008), o abandono das atividades de mineração, deixando as áreas com solo exposto, propicia a instalação de processos erosivos com intensidade variável, além de alagamento e assoreamento de cursos de água, que acentuam ainda mais o desequilíbrio ambiental. Rocha (2011) destaca, ainda, que a ocupação das encostas e a atividade de mineração corroboram para a ocorrência de pequenos escorregamentos, que acabam refletindo na dinâmica hidrológica e sedimentar dos canais fluviais.

Nesse sentido, o processo de degradação do rio Maranduba é perceptível, através da ocupação inadequada de suas margens. Parece haver a diminuição da quantidade de água, a erosão das margens com a retirada da mata ciliar, o que pode resultar no assoreamento do mesmo (Figura 7). Áreas próximas à orla na bacia do rio Maranduba foram aterradas e, atualmente, sofrem com alagamentos, além da contaminação das águas do rio, com o despejo de esgoto e efluentes oriundos da ocupação irregular, tornando necessário, assim, medidas urgentes de recuperação ambiental. As intervenções no uso e ocupação do solo têm ocasionado impactos negativos na rede de drenagem, sobretudo na planície costeira da área de estudo, uma vez que o processo de ocupação desordenado se intensifica nesta área.

\begin{tabular}{llllll}
\hline Caminhos de Geografia & Uberlândia - MG & v. 19, n. 67 & Set/2018 & p. 157-174 & Página 167
\end{tabular}


Figura 7: Ocupação desordenada do rio Maranduba (A); margens erodidas (B).

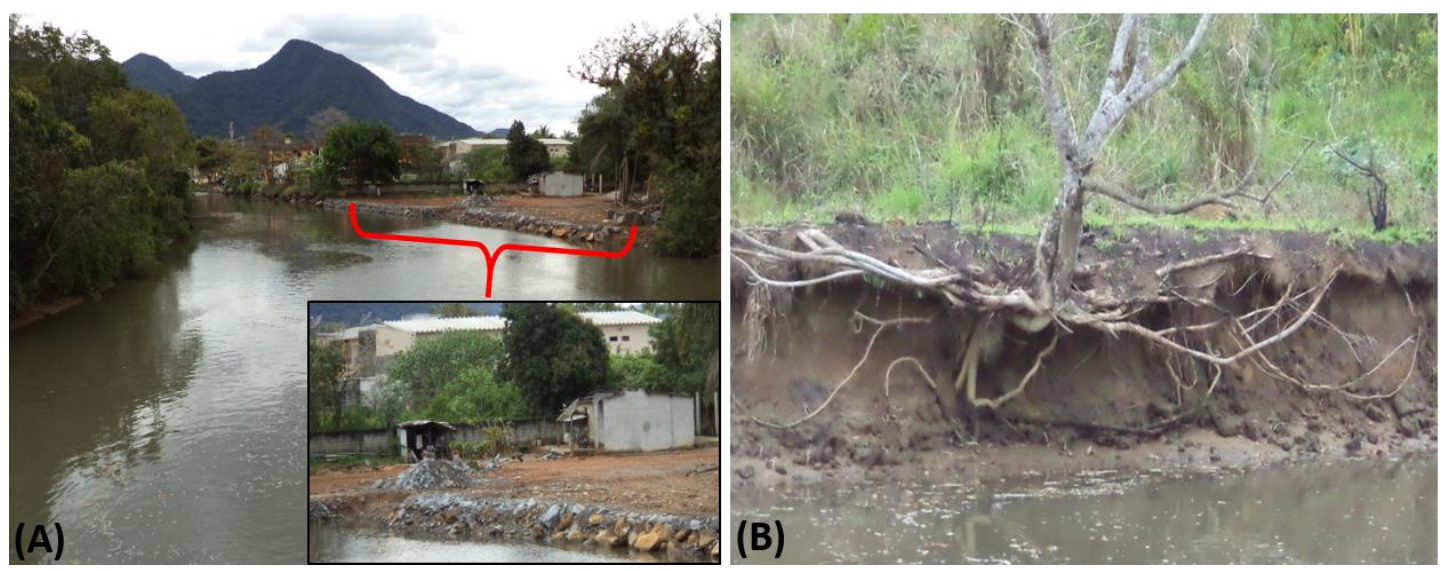

Fotos: ALINE M. RODRIGUES (2015).

Portanto, na bacia hidrográfica do rio Maranduba o processo de degradação ambiental está relacionado, sobretudo, à ocupação irregular e à exploração mineral, colocando em risco a perenidade de inestimável biodiversidade, em um ambiente que naturalmente apresenta elevada fragilidade. Salienta-se a necessidade de promover o uso adequado do solo em bacias hidrográficas, de modo a minimizar possíveis desequilíbrios, visto que os impactos gerados à montante têm reflexos à jusante. Sendo que os sistemas ambientais possuem comportamentos de sistemas dinâmicos, com elevadas interações, fluxos de matéria e energia e retroalimentação, além da influência exercida pelo sistema antrópico, à medida que o homem pode ser considerado um agente transformador da estrutura e funcionamento dos sistemas ambientais, provocando modificações, em muitos casos, irreversíveis (CHRISTOFOLETTI, 1999; FIERZ, 2008; CHRISTOPHERSON, 2012).

\section{CONSIDERAÇÕES FINAIS}

A remoção da cobertura vegetal, aliado às características naturais da área de estudo, como forte declividade e pluviosidade elevada, corroboram para a ocorrência de impactos ambientais, sobretudo associados à perda da qualidade dos solos. A exploração mineral provoca alterações na geometria das encostas, originando taludes íngremes e instáveis, com remoção da vegetação e exposição de solo e saprolito. A situação tende a ser agravada pelo posterior abandono desses taludes, levando ao desequilíbrio ambiental, com a intensificação dos processos erosivos e movimentos de massa.

As análises físicas e químicas dos solos de taludes parecem demonstrar como áreas situadas na borda do Parque Estadual da Serra do Mar estão sendo impactadas negativamente com o uso indevido da atividade mineradora, uma vez que, ao retirarem as camadas mais superficiais do solo, que tendem a ser mais eficientes para a contenção dos processos erosivos, expõem camadas do sistema solo com menor resistência frente aos agentes modeladores do relevo, corroborando na intensificação dos processos erosivos devido a menor estabilidade dos agregados, bem como na menor concentração de matéria orgânica em camadas mais subsuperficiais.

Este estudo almeja contribuir para o melhor entendimento ambiental da bacia e alertar para a necessidade de proteção de importante recurso natural, o solo, além da conservação da biodiversidade formada pelo ameaçado bioma da Mata Atlântica, onde a ação fiscalizadora da Prefeitura, em conjunto com a comunidade local, possui inestimável importância para a conservação ambiental da bacia.

\section{AGRADECIMENTOS}

Agradecimento à CAPES e à parceria CAPES/EMBRAPA pela concessão das bolsas de pósgraduação.

$\begin{array}{llllll}\text { Caminhos de Geografia } & \text { Uberlândia - MG } & \text { v. 19, n. } 67 & \text { Set/2018 } & \text { p. 157-174 } & \text { Página } 168\end{array}$




\section{REFERÊNCIAS}

BHATTACHARYYA, R. et al. Soil Conservation Issues in India. Sustainability, 8, 565, 2016. doi:10.3390/su8060565. https://doi.org/10.3390/su8060565

BRADY, N. C. The nature and properties of soils. Rio de Janeiro: Freitas Bastos, 1989.

BRADY, N. C.; WEIL, R. R. The nature and properties of soil. 14 ed. Upper Saddle River, NJ: Pearson-Prentice Hall, 990p. 2008.

BUZATO, E. Avaliação de impactos ambientais no município de Ubatuba: uma proposta a partir dos geoindicadores. Tese (doutorado) - Universidade de São Paulo, 2012.

CAMARGO, O. A.; ALLEONI, L. R. F. Compactação do solo e o desenvolvimento das plantas. Piracicaba: [s.n.], 132 p. 1997.

CARVALHO, C.S. Matéria orgânica, agregação e proteção física em solos tratados com lodo de esgoto. Tese (doutorado) - Agricultura Tropical e Subtropical - Instituto Agronômico, 2015.

CARVALHO, M.A.; RUIZ, H.A.; COSTA, L.M.; PASSO, R.R.; ARAUJO, C.A.S. Composição granulométrica, densidade e porosidade de agregados de Latossolo Vermelho sob duas coberturas do solo. Revista Brasileira de Engenharia Agrícola e Ambiental. v.18, n.10, p.1010-1016, 2014. https://doi.org/10.1590/1807-1929/agriambi.v18n10p1010-1016

CASTRO FILHO, C.; MUZILLI, O.; PODANOSCHI, A. L. Estabilidade dos agregados e sua relação com o teor de carbono orgânico num Latossolo Roxo Distrófico, em função de sistemas de plantio, rotações de culturas e métodos de preparo das amostras. Revista Brasileira de Ciência do Solo, v. 22, p. 527-538, 1998. https://doi.org/10.1590/S0100-06831998000300019

CHENG, C.-H.; HSIAO, S.-C.; HUANG, Y.-S.; HUNG, C.-Y.; PAI, C.-W.; CHEN, C.-P.; MENYAILO, O.V. Landslide-induced changes of soil physicochemical properties in Xitou, Central Taiwan.

Geoderma 265,187-195. 2016. https://doi.org/10.1016/j.geoderma.2015.11.028

CHRISTOFOLETTI, A. Modelagem de Sistemas Ambientais. SP. Edgard Blücher Ltda, 1999.

CHRISTOPHERSON, R.W. Geossistemas - Uma Introdução à Geografia Física. Porto Alegre: Bookman, $7^{\circ}$ edição, 2012.

CUNHA, M.A.; FARAH, F; CERRI, L.E.S.; GOMES, L.A.; GALVÊS, M.L.; BITTAR, O.Y.; FILHO, O.A.; SILVA, W.S. Ocupação de encostas. São Paulo: IPT, 216p. 1991.

EMBRAPA. Centro Nacional de Pesquisa de Solos (Rio de Janeiro, RJ). Manual de métodos de análise de solo / Centro Nacional de Pesquisa de Solos - 2. ed. Ver. Atual. - Rio de Janeiro, 2011.

FERREIRA, C. J.; BROLLO, M. J.; UMMUS, M. E.; NERY, T. D. Indicadores e quantificação da degradação ambiental em áreas mineradas, Ubatuba (SP). Revista Brasileira de Geociências, volume 38 (1), 2008. https://doi.org/10.25249/0375-7536.2008381141152

FERREIRA, S.L.S.; OKA-FIORI, C.; KOZCIAK, S. Análise multitemporal da erosão nas bacias hidrográficas dos rios São João, Iporã e do Prado, Altônia - PR, decorrente da dinâmica agropastoril. Caminhos de Geografia, Uberlândia, v. 13, n. 44, p. 15-34. 2012.

FIERZ, M.S.M. As abordagens sistêmica e do equilíbrio dinâmico na análise da fragilidade ambiental do litoral do estado de São Paulo: contribuição à geomorfologia das planícies costeiras. Tese (doutorado) - Universidade de São Paulo, 2008.

FONTANA, A.; BRITO, R.J.; PEREIRA, M.G.; LOSS, A. Índices de agregação e a relação com as substâncias húmicas em Latossolos e Argissolos de tabuleiros costeiros, Campos dos Goytacazes, RJ. Revista Brasileira de Ciências Agrárias, v.5, p.291-297, 2010. https://doi.org/10.5039/agraria.v5i3a461

FULLEN, M. A.; CATT, J. A. Soil management: problems and solutions. Arnold Publishers, London: 269 pp. 2004.

GONZÁLEZ-ARQUEROS, M.L.; MENDOZA, M.E.; VÁZQUEZ-SELEM, L. Human impact on natural systems modeled through soil erosion in GeoWEPP: A comparison between pre-Hispanic periods and modern times in the Teotihuacan Valley (Central Mexico). Catena, 149, 505-513. 2017. https://doi.org/10.1016/j.catena.2016.07.028 
GOUDIE, A. The changing Earth-Rates of Geomorphological Processes. Oxford, Blackwell Publishers, 302p. 1995.

GUERRA, A. J. T. Degradação dos solos - conceitos e temas. In: GUERRA, A. J. T.; JORGE, M. C.O. (Orgs.). Degradação dos solos no Brasil. Ed. Bertrand Brasil. 1ํe edição, 2014.

GUERRA, A.J.T.; CUNHA, S.B. Geomorfologia e meio ambiente. Rio de Janeiro: Bertrand Brasil, 1996.

GUERRA, A.J.T.; FULLEN, M.A.; JORGE, M.C.O.; BEZERRA, J.F.R.; SHOKR, M.S. Slope processes, mass movements and soil erosion: a review. Pedosphere, v. 27, p. 27-41, 2017.

https://doi.org/10.1016/S1002-0160(17)60294-7

GUERRA, A. T.; GUERRA, A. J. T. Novo dicionário geológico-geomorfológico. 9. ed. Rio de Janeiro: Bertrand Brasil, 2013.

HASUI, Y. et al. Mapa geológico do pré-cambriano em São Paulo, 1:500.000.

UNESP/PROMINER/DNPM, Rio Claro, 1993.

HASUI, Y.; DANTAS, A. S. L.; CARNEIRO, C. D. R.; BISTRICHI, C. A. O embasamento précambriano e paleozoico em São Paulo. In: IPT. Mapa geológico do Estado de São Paulo. Escala 1:500.000. São Paulo, IPT Governo do Estado de São Paulo. Secretaria da Indústria, Comércio, Ciência e Tecnologia. (Série Monografias V1), 1981.

IPT - INSTITUTO DE PESQUISAS TECNOLÓGICAS DE SÃO PAULO. Mineração e município: bases para planejamento e gestão dos recursos minerais. São Paulo, 2003.

JORGE, M. C. O. Degradação dos solos no litoral norte paulista. In: GUERRA, A. J. T.; JORGE, M. C. O. (Orgs.). Degradação dos solos no Brasil. Ed. Bertrand Brasil. 1ํe edição, 2014.

JORGE, M.C.O. Potencial geoturístico e estratégias de geoconservação em trilhas situadas na região sul do município de Ubatuba - SP. Tese de doutorado, Programa de Pós-graduação em Geografia - Universidade Federal do Rio de Janeiro, Instituto de Geociências, Rio de Janeiro, 2017.

KIEHL, E. J. Manual de edafologia, relações solo-planta. São Paulo: Ceres, 1979.

KLEIN, C.; KLEIN, V.A. Estratégias para potencializar a retenção e disponibilidade de água no solo. Revista Eletrônica em Gestão, Educação e Tecnologia Ambiental - REGET. V. 19, n. 1, p.21-29. 2015.

KLIK, A.; EITZINGER, J. Climate change and agriculture paper impact of climate change on soil erosion and the efficiency of soil conservation practices in Austria. Journal of Agricultural Science, 148, 529-541. 2010. https://doi.org/10.1017/S0021859610000158

LIMA, C. L. R.; PAULETTO, E. A.; GOMES, A. S.; SILVA, J. B. Estabilidade de agregados de um Planossolo sob diferentes sistemas de manejo. Revista Brasileira de Ciência do Solo, 27, p.199205. 2003. https://doi.org/10.1590/S0100-06832003000100021

MARCHINI, D.C.; LING, T.C.; ALVES, M.C. CRESTANA, S.; FILHO, S.N.S.; ARRUDA, O.G. Matéria orgânica, infiltração e imagens tomográficas de latossolo em recuperação sob diferentes tipos de manejo. R. Bras. Eng. Agríc. Ambiental, v.19, n.6, p.574-580, 2015.

McQUEEN, K.G.; SCOTT, K.M. Rock weathering and structure of the regolith. In: SCOTT, K.; PAIN, C.F. (eds.). Regolith Science. Dordrecht, Springer Science and CSIRO, The Netherlands, and Collingwood, Australia Publ., Australia, Springer, 462 p. 2009.

MIELNICZUK, J. Matéria orgânica e sustentabilidade de sistemas agrícolas. In: SANTOS, G.A. et al. Fundamentos da matéria orgânica do solo: ecossistemas tropicais e subtropicais. $2^{\circ}$ ed. Porto Alegre: Metrópole, p.1-5. 2008.

MORGAN, R.P.C.; RICKSON, R.J. Slope stabilization and erosion control: a bioengineering approach. London: E \& FN Spon, 274p. 1995.

MORGAN, R.P.C. Soil Erosion and Conservation. England: Blackwell, 2005. https://doi.org/10.4324/9780203362136

NANDI, A.; LUFFMAN, I. Erosion Related Changes to Physicochemical Properties of Ultisols Distributed on Calcareous Sedimentary Rocks. Journal of Sustainable Development; v. 5, n. 8; 2012. https://doi.org/10.5539/jsd.v5n8p52

$\begin{array}{llllll}\text { Caminhos de Geografia } & \text { Uberlândia - MG } & \text { v. 19, n. } 67 & \text { Set/2018 } & \text { p. 157-174 } & \text { Página } 170\end{array}$


PEREIRA, L.S. Análises físico-químicas de solos com distintas coberturas vegetais e processos hidroerosivos em área degradada na bacia do rio Maranduba - Ubatuba, São Paulo. Dissertação (Mestrado em Geografia) - Universidade Federal do Rio de Janeiro, Instituto de Geociências, Rio de Janeiro, 2015.

PEREIRA, L.S.; RODRIGUES, A.M.; JORGE, M.C.O.; GUERRA, A.J.T.; FULLEN, M.A. Hydro-erosive processes in degraded soils on gentle slopes. Revista Brasileira de Geomorfologia, 17(2), 299-316. 2016. ISSN 2236-5664.

PIMENTEL, D. Soil Erosion: A Food and Environmental Threat. Environmental Development and Susteinability (8), 119-137, 2006.

PORTUGAL, A.F.; JUNCKSH, I.; SCHAEFER, C.E.R.G.; NEVES, J.C.L. Estabilidade de agregados em Argissolo sob diferentes usos, comparado com mata. Revista Ceres, Viçosa, n.4, v.57, p.545553, 2010.

PREVEDELLO, C.L. Física do solo com problemas resolvidos. Curitiba: SAEAFS, 446 p. 1996.

REICHERT, J. M.; REINERT, J. D.; SUZIKI, L. E. A. S.; HORN, R. Mecânica do solo. In: LIER, Q. J. V. (editor) Física do solo. Viçosa: Sociedade Brasileira de Ciência do Solo, p. 29 - 102. 2010.

ROCHA, K.N.D. Relação entre a vulnerabilidade social e a fragilidade ambiental no Litoral Norte Paulista: o caso dos municípios de Ilhabela, São Sebastião, Caraguatatuba e Ubatuba. Dissertação (mestrado) - Universidade Estadual de Campinas, Instituto de Geociências, 2011.

RODRIGUES, A.M. Diagnóstico da Degradação do Solo de Taludes de Corte na Bacia Hidrográfica do Rio Maranduba - Ubatuba/SP. Dissertação de Mestrado, Programa de PósGraduação em Geografia, Instituto de Geociências, Universidade Federal do Rio de Janeiro, 2016.

RODRIGUES, A.M.; RANGEL, L.A.; PEREIRA, L.S.; JORGE, M.C.O.; MOLINARO, Y.T.; GUERRA, A.J.T. Degradação dos solos em diferentes usos (trilha e taludes de corte) em Unidades de Conservação. Anais do XI SINAGEO, Simpósio Nacional de Geomorfologia. 2016.

ROSSI, M. Fatores formadores da paisagem litorânea: a bacia do Guaratuba, São Paulo Brasil.159p. Tese (Doutorado em Geografia Física) Faculdade de Filosofia, Letras e Ciências Humanas, Universidade de São Paulo, São Paulo, 1999.

SANT'ANNA NETO, J. L. Ritmo climático e a gênese das chuvas na zona costeira paulista. Dissertação (Mestrado). Faculdade de Filosofia, Letras e Ciências Humanas, Universidade de São Paulo, São Paulo. 1990.

SANTOS, A. R. dos. A grande barreira da Serra do Mar: da trilha dos tupiniquins à Rodovia dos Imigrantes. São Paulo: Editora O Nome da Rosa, 122 p., 2004.

SILVA, F.L.M. O risco geológico associado à ocupação de áreas de mineração no município de Ubatuba (SP). Dissertação (mestrado) - Universidade Estadual de Campinas. Instituto de Geociências, 1995.

SILVA, I. F.; MIELNICZUK, J. Ação do sistema radicular de plantas na formação e estabilização de agregados do solo. Revista Brasileira de Ciência do Solo, v.21, p.113-117, 1997.

SUZUKI, L.E.A.S.; LIMA, C.L.R.; REINERT, D.J.; REINERT, J.M.; PILLON, C.N. Estrutura e armazenamento de água em um argissolo sob pastagem cultivada, floresta nativa e povoamento de eucalipto no Rio Grande do Sul. Revista Brasileira de Ciência do Solo, 38:94-106, 2014. https://doi.org/10.1590/S0100-06832014000100009

SUZUKI, L.E.A.S.; REINERT, D.J.; REICHERT, J.M.; LIMA, C.L.R. de. Estimativa da susceptibilidade à compactação e do suporte de carga do solo com base em propriedades físicas de solos do Rio Grande do Sul. Revista Brasileira de Ciência do Solo [online], v.32, n.3. 2008. https://doi.org/10.1590/S0100-06832008000300006

TAVARES, R.; SANT'ANNA NETO, J. L.; SANTORO, J. Chuvas e escorregamentos no Litoral Norte Paulista entre 1988 e 2001. In: Anais do Encontro de Geógrafos Brasileiros. João Pessoa: AGBDER, 2002.

TOMINAGA, L. K. Avaliação de metodologias de análise de risco a escorregamentos: aplicação de um ensaio em Ubatuba, SP. Tese (doutorado) - Universidade de São Paulo, 2007. 
TORRES, J.L.R.; PEREIRA, M.G.; ASSIS, R.L. de.; SOUZA, Z.M. de. Atributos físicos de um latossolo vermelho cultivado com plantas de cobertura, em semeadura direta. Revista Brasileira de Ciência do Solo, 39:428-437, 2015. https://doi.org/10.1590/01000683rbcs20140597

VEZZANI, F. M.; MIELNICZUK, J. Agregação e estoque de carbono em Argissolo submetido a diferentes práticas de manejo agrícola. Revista Brasileira de Ciência do Solo, v.35, p.213-223, 2011. https://doi.org/10.1590/S0100-06832011000100020

WINCK, B.R.; VEZZANI, F.M.; DIECKOW, J.; FAVARETTO, N.; MOLIN, R. Carbono e nitrogênio nas frações granulométricas da matéria orgânica do solo, em sistemas de culturas sob plantio direto.

Revista Brasileira de Ciência do Solo, 38:980-989, 2014. https://doi.org/10.1590/S0100$\underline{06832014000300030}$

YODER, R. E. A direct method of aggregate analysis of soils and a study of the physical nature of erosion losses. Journal American Society Agronomy. v. 28, p. 337- 351. 1936.

https://doi.org/10.2134/agronj1936.00021962002800050001x

ZINN, Y. L.; LAL, R.; BIGHAM, J. M.; RESCK, D. V. S. Edaphic controls on soil organic carbon retention in the Brazilian Cerrado: soil structure. Soil Science Society of America Journal. Madison, v. 71 , n. 4, p. 1215-1224, 2007.

ZINN, Y. L.; LAL, R.; RESCK, D. V. S. Eucalypt plantation effects on organic carbon and aggregation of three different-textured soils in Brazil. Soil Research, Collingwood, v. 49, n. 7, p. 614-624, 2011. https://doi.org/10.1071/SR11264

Recebido em: 28/08/2017

Aceito para publicação em: 25/04/2018 
Tabela 1: Valores da precipitação média (milímetros e percentual) para os meses de janeiro a dezembro entre 2009 e 2015 e médias mensais anuais de 7 anos comparados com a série histórica de 30 anos do município de Ubatuba do banco de dados climáticos do Brasil.

\begin{tabular}{|c|c|c|c|c|c|c|c|c|c|c|c|c|c|c|c|c|c|c|}
\hline \multirow{2}{*}{ Meses } & \multicolumn{2}{|c|}{2009} & \multicolumn{2}{|c|}{2010} & \multicolumn{2}{|c|}{2011} & \multicolumn{2}{|c|}{2012} & \multicolumn{2}{|c|}{2013} & \multicolumn{2}{|c|}{2014} & \multicolumn{2}{|c|}{2015} & \multicolumn{2}{|c|}{$\begin{array}{l}\text { Média de } 7 \\
\text { anos }\end{array}$} & \multicolumn{2}{|c|}{$\begin{array}{c}\text { Média de } 30 \\
\text { anos (1961-1991) }\end{array}$} \\
\hline & $\mathrm{mm}$ & $\%$ & $\mathrm{~mm}$ & $\%$ & $\mathrm{~mm}$ & $\%$ & $\mathrm{~mm}$ & $\%$ & $\mathrm{~mm}$ & $\%$ & $\mathrm{~mm}$ & $\%$ & $\mathbf{m m}$ & $\%$ & $\mathrm{~mm}$ & $\%$ & $\mathrm{~mm}$ & $\%$ \\
\hline janeiro* & 223,1 & 9,5 & 456,9 & 18,9 & 231,6 & 10,0 & 220,2 & 12,8 & 495,1 & 24,9 & 122,5 & 7,6 & 191,8 & 13,3 & 277,3 & 14,0 & 376,0 & 14,9 \\
\hline fevereiro & 191,0 & 8,2 & 198,3 & 8,2 & 149,9 & 6,5 & 228,3 & 13,2 & 92,1 & 4,6 & 132,0 & 8,2 & 153,6 & 10,7 & 163,6 & 8,3 & 302,0 & 12,0 \\
\hline março & 91,6 & 3,9 & 227,2 & 9,4 & 604,9 & 26,2 & 112,4 & 6,5 & 267,6 & 13,4 & 252,8 & 15,6 & 230,9 & 16,0 & 255,3 & 12,9 & 300,0 & 11,9 \\
\hline abril & 276,7 & 11,8 & 206,0 & 8,5 & 394,0 & 17,0 & 79,2 & 4,6 & 46,7 & 2,3 & 226,0 & 14,0 & 94,8 & 6,6 & 189,1 & 9,6 & 241,0 & 9,6 \\
\hline maio & 166,5 & 7,1 & 107,0 & 4,4 & 11,0 & 0,5 & 193,0 & 11,2 & 169,3 & 8,5 & 82,0 & 5,1 & 36,4 & 2,5 & 109,3 & 5,5 & 124,0 & 4,9 \\
\hline junho* & 99,7 & 4,3 & 171,5 & 7,1 & 56,9 & 2,5 & 151,1 & 8,8 & 89,3 & 4,5 & 94,1 & 5,8 & 153,4 & 10,6 & 116,6 & 5,9 & 87,0 & 3,5 \\
\hline julho* & 209,7 & 9,0 & 219,0 & 9,0 & 45,5 & 2,0 & 179,7 & 10,4 & 135,7 & 6,8 & 179,8 & 11,1 & 19,0 & 1,3 & 141,2 & 7,1 & 11,0 & 0,4 \\
\hline agosto & 82,0 & 3,5 & 64,6 & 2,7 & 116,5 & 5,0 & 15,5 & 0,9 & 27,5 & 1,4 & 83,9 & 5,2 & 25,0 & 1,7 & 59,3 & 3,0 & 93,0 & 3,7 \\
\hline setembro & 162,3 & 6,9 & 166,5 & 6,9 & 121,4 & 5,2 & 41,7 & 2,4 & 93,5 & 4,7 & 111,5 & 6,9 & 107,5 & 7,5 & 114,9 & 5,8 & 166,0 & 6,6 \\
\hline outubro & 287,7 & 12,3 & 95,7 & 4,0 & 160,0 & 6,9 & 138,3 & 8,0 & 199,0 & 10,0 & 68,2 & 4,2 & 117,3 & 8,1 & 152,3 & 7,7 & 215,0 & 8,5 \\
\hline novembro & 130,0 & 5,6 & 175,5 & 7,2 & 90,9 & 3,9 & 204,0 & 11,8 & 183,5 & 9,2 & 116,7 & 7,2 & 120,3 & 8,4 & 145,8 & 7,4 & 256,0 & 10,2 \\
\hline dezembro* & 416,2 & 17,8 & 332,1 & 13,7 & 230,4 & 10,0 & 160,0 & 9,3 & 191,7 & 9,6 & 149,3 & 9,2 & 190,5 & 13,2 & 238,6 & 12,1 & 348,0 & 13,8 \\
\hline Total & 2336,5 & 100,0 & 2420,8 & 100,0 & 2312,6 & 100,0 & 1723,4 & 100,0 & 1991,0 & 100,0 & 1618,8 & 100,0 & 1440,5 & 100,0 & 1977,7 & 100,0 & 2.519 & 100,0 \\
\hline
\end{tabular}

Fonte: Pereira (2015). 
Tabela 3: Propriedades químicas e físicas das amostras analisadas.

\begin{tabular}{|c|c|c|c|c|c|c|c|c|c|c|c|c|}
\hline \multirow{2}{*}{\multicolumn{2}{|c|}{ AMOSTRAS }} & \multicolumn{4}{|r|}{ Textura $(\bar{x})$} & \multirow{3}{*}{$\begin{array}{c}\mathrm{DS}\left(\mathrm{g} / \mathrm{cm}^{3}\right) \\
\overline{\mathrm{x}} \\
1,4\end{array}$} & \multirow{3}{*}{$\begin{array}{c}\text { PT (\%) } \\
\bar{x} \\
48,1\end{array}$} & \multirow{3}{*}{$\begin{array}{c}\text { MO (\%) } \\
\underline{\bar{x}} \\
0,3\end{array}$} & \multirow{3}{*}{$\begin{array}{r}\mathrm{pH} \\
\overline{\mathrm{x}} \\
5,1\end{array}$} & \multicolumn{3}{|c|}{ Estabilidade de Agregados $(\overline{\mathrm{x}})$} \\
\hline & & \multirow{2}{*}{$\begin{array}{c}\text { Areia \% } \\
65,2\end{array}$} & \multirow{2}{*}{$\begin{array}{c}\text { Silte } \% \\
17,4\end{array}$} & \multirow{2}{*}{$\frac{\text { Argila } \%}{17,4}$} & \multirow{2}{*}{$\begin{array}{c}\text { Classificação Textural } \\
\text { Franco arenoso - sandy loam }\end{array}$} & & & & & DMP (mm) & DMG (mm) & IEA (\%) \\
\hline \multirow{10}{*}{$\mathbf{A D}$} & P1 & & & & & & & & & 1,0 & 0,5 & 45,1 \\
\hline & P2 & 58,3 & 13,0 & 28,7 & Franco areno-argiloso - sandy clay loam & 1,3 & 50,4 & 1,4 & 4,3 & 2,3 & 2,0 & 92,2 \\
\hline & P3 & 56,7 & 12,0 & 31,4 & Franco areno-argiloso - sandy clay loam & 1,5 & 45,4 & 0,5 & 4,6 & 1,0 & 0,5 & 53,2 \\
\hline & P4 & 66,9 & 16,2 & 16,9 & Franco arenoso - sandy loam & 1,6 & 40,1 & 0,7 & 4,7 & 1,5 & 0,9 & 68,7 \\
\hline & P5 & 36,2 & 8,7 & 55,1 & Argiloso - clay & 1,3 & 51,5 & 1,2 & 4,2 & 0,9 & 0,5 & 49,6 \\
\hline & P6 & 46,3 & 17,2 & 36,5 & Franco argiloso - sandy clay & 1,4 & 47,1 & 0,4 & 5,1 & 0,8 & 0,4 & 45,7 \\
\hline & P7 (0-20) & 64,8 & 20,0 & 15,2 & Franco arenoso - sandy loam & 1,3 & 48,2 & 5,0 & 3,6 & 2,6 & 2,2 & 93,7 \\
\hline & P7 (20-40) & 55,7 & 12,8 & 31,5 & Franco areno-argiloso - sandy clay loam & 1,6 & 38,8 & 2,3 & 3,7 & 1,3 & 0,8 & 66,1 \\
\hline & P8 (0-20) & 45,0 & 31,3 & 23,8 & Franco - loam & 0,9 & 61,4 & 7,6 & 3,5 & 2,8 & 2,6 & 96,9 \\
\hline & P8 (20-40) & 41,9 & 16,5 & 41,5 & Argiloso - clay & 1,3 & 47,4 & 2,1 & 4,0 & 1,0 & 0,6 & 53,5 \\
\hline \multirow{2}{*}{ AF } & P9 (0-20) & 54,4 & 22,5 & 23,0 & Franco areno-argiloso - sandy clay loam & 1,1 & 52,0 & 11,0 & 4,2 & 2,9 & 2,8 & 98,2 \\
\hline & P10 (0-20) & 50,6 & 23,2 & 26,2 & Franco areno-argiloso - sandy clay loam & 1,2 & 51,0 & 9,3 & 5,0 & 2,5 & 2,0 & 90,3 \\
\hline \multicolumn{13}{|c|}{$\mathrm{AD}=$ Áreas Degradadas $\quad \mathrm{AF}=$ Áreas de Floresta } \\
\hline & $\overline{\mathbf{x}}:$ Média & : Densida & le Aparer & PT: Pol & $\begin{array}{r}\text { MO: Matéria Orgânica DMP } \\
\text { Estabilidade de Agr }\end{array}$ & $\begin{array}{l}\text { Diâmetro Méc } \\
\text { gados }\end{array}$ & o Ponder & DMG & âmetı & Médio Geom & trico IEA: Ín & e de \\
\hline
\end{tabular}

